University of Nebraska - Lincoln

DigitalCommons@University of Nebraska - Lincoln

2004

Stress-induced, time-dependent fracture closure at hydrothermal conditions

\author{
N. M. Beeler \\ U.S. Geological Survey \\ S. H. Hickman \\ U.S. Geological Survey
}

Follow this and additional works at: https://digitalcommons.unl.edu/usgsstaffpub

Part of the Earth Sciences Commons

Beeler, N. M. and Hickman, S. H., "Stress-induced, time-dependent fracture closure at hydrothermal conditions" (2004). USGS Staff -- Published Research. 415.

https://digitalcommons.unl.edu/usgsstaffpub/415

This Article is brought to you for free and open access by the US Geological Survey at DigitalCommons@University of Nebraska - Lincoln. It has been accepted for inclusion in USGS Staff -- Published Research by an authorized administrator of DigitalCommons@University of Nebraska - Lincoln. 


\title{
Stress-induced, time-dependent fracture closure at hydrothermal conditions
}

\author{
N. M. Beeler and S. H. Hickman \\ U.S. Geological Survey, Menlo Park, California, USA
}

Received 23 January 2002; revised 1 May 2003; accepted 10 July 2003; published 28 February 2004.

[1] Time-dependent closure of fractures in quartz was measured in situ at $22-530^{\circ} \mathrm{C}$ temperature and $0.1-150 \mathrm{MPa}$ water pressure. Unlike previous crack healing and rock permeability studies, in this study, fracture aperture is monitored directly and continuously using a windowed pressure vessel, a long-working-distance microscope, and reflectedlight interferometry. Thus the fracture volume and geometry can be measured as a function of time, temperature, and water pressure. Relatively uniform closure occurs rapidly at temperatures and pressures where quartz becomes significantly soluble in water. During closure the aperture is reduced by as much as $80 \%$ in a few hours. We infer that this closure results from the dissolution of small particles or asperities that prop the fracture open. The driving force for closure via dissolution of the prop is the sum of three chemical potential terms: (1) the dissolution potential, proportional to the logarithm of the degree of undersaturation of the solution; (2) the coarsening potential, proportional to the radius of curvature of the prop; and (3) the pressure solution potential, proportional to the effective normal stress at the contact between propping particles and the fracture wall. Our observations suggest that closure is controlled by a pressure solution-like process. The aperture of dilatant fractures and microcracks in the Earth that are similar to those in our experiments, such as ones generated from thermal stressing or brittle failure during earthquake rupture and slip, will decrease rapidly with time, especially if the macroscopic stress is nonhydrostatic. INDEX TERMS: 5104 Physical Properties of Rocks: Fracture and flow; 5114 Physical Properties of Rocks: Permeability and porosity; 8010 Structural Geology: Fractures and faults; 8045 Structural Geology: Role of fluids; KEYWORDS: crack healing, crack closure, hydrothermal

Citation: Beeler, N. M., and S. H. Hickman (2004), Stress-induced, time-dependent fracture closure at hydrothermal conditions, J. Geophys. Res., 109, B02211, doi:10.1029/2002JB001782.

\section{Introduction}

[2] If crustal temperature and pressure are high enough that minerals are significantly soluble, and if fluid is available, fault zone physical properties can be substantially altered by solution mass transport processes. Such processes consist of sequential dissolution, transportation, and precipitation of minerals driven by spatial variation in chemical potential. Differences in chemical potential can arise because of gradients in stress (pressure solution), surface curvature (crack healing), or temperature. Significant changes in fault zone permeability and porosity could result from solution mass transfer processes; for example, interseismic fault zone fluid pressure could increase with time through the simultaneous operation of crack healing, which can rapidly reduce the permeability [Brantley et al., 1990], and pressure solution compaction [Sleep and Blanpied, 1992]. Fault strength may also increase rapidly through an increase in the load-bearing contact area via contact overgrowths [Hickman and Evans, 1992]. However, the rates of these processes in relevant fault zone rocks and minerals are

This paper is not subject to U.S. copyright.

Published in 2004 by the American Geophysical Union. unconstrained. To begin to determine if natural conditions exist where solution mass transport phenomena are relevant to interseismic fault zone properties, we have conducted a quantitative experimental study of these processes in quartz.

[3] In the current study we directly measure the rate of fracture closure, an apparently previously unrecognized example of solution mass transport, at hydrothermal conditions. The temporal evolution of the aperture of dilatant fractures in quartz was measured in situ at $22-530^{\circ} \mathrm{C}$ temperature and $0.1-150 \mathrm{MPa}$ water pressure in a windowed pressure vessel. The fractures used in these experiments are not internally supported by pressure in excess of the confining pressure; instead, they are held open by debris between, or asperities on, opposing sides of the fracture. Results show that fracture volume decreases rapidly with time at temperatures $>300^{\circ} \mathrm{C}$. Using existing models of pressure solution, we develop a model for closure that is consistent with the observations.

\section{Experiments}

[4] Samples are fractured prisms of synthetic quartz (Figure 1) manufactured from a single quartz crystal synthesized by P. R. Hoffman Inc., Carlisle, Pennsylvania. 

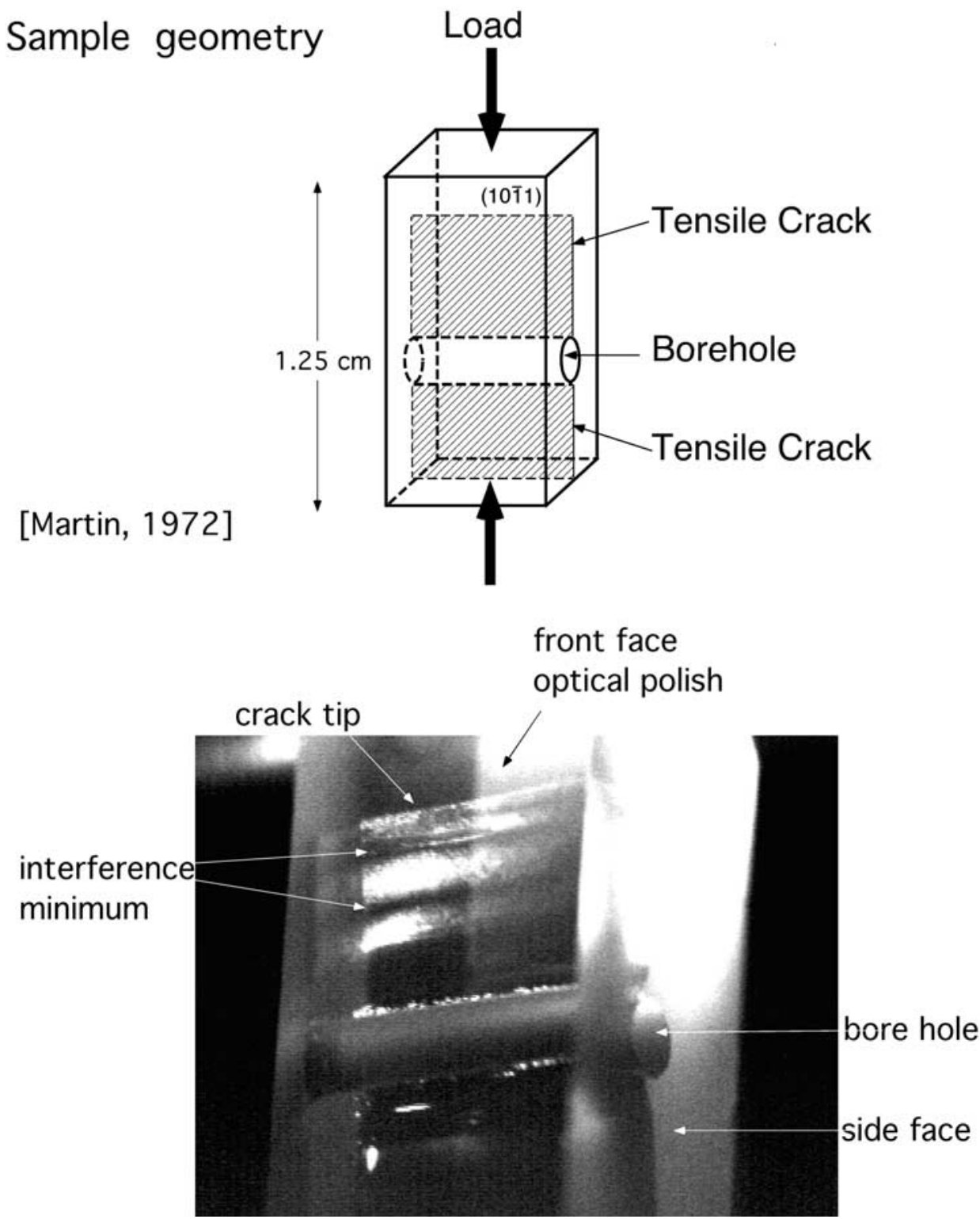

Figure 1. Sample geometry of a cracked prism of synthetic quartz. Schematic shows the load used to generate the crack.

Prisms were cut with a wire saw, and prism surfaces were ground successively by hand on a glass plate with 400 grit, 600 grit, $13.5 \mu \mathrm{m}$, and $5 \mu \mathrm{m}$ silica carbide. Fractures within the prism were generated by loading a cylindrical borehole normal to its axis [Martin, 1972]. The borehole was oriented to lie in the plane $(10 \overline{1} 1)$, and induced tensile cracks emanating from the borehole were subparallel to (1011). Boreholes were drilled near one end of the prism and clamped normal to $(10 \overline{1} 1)$ at the opposite end during loading so that the fracture intersected the prism end nearest the borehole. The (1011) faces of the prism were polished to an optical finish with $1 \mu \mathrm{m}$ cesium oxide prior to fracture generation so that the fracture surface could be viewed through the faces.

[5] Experiments were conducted in deionized water in a passivated Rene 41 pressure vessel that has a sapphire window in the base (Figure 2). Samples within the vessel lie on one of the polished faces on top of the window and are illuminated from below by a tunable monochromatic light source that has a wavelength range of $600-360 \mathrm{~nm}$. The vessel contained additional quartz in varying amounts (Table 1, see also section 4). This additional quartz increases the available surface area for quartz dissolution required to bring the solution to saturation; thus relatively little mass is lost from the sample prisms during the experiments (Table 1). In the first set of experiments a fixed amount of extra quartz was added. This quartz was from the same synthetic crystal used to make the sample prisms. A second suite of experiments was conducted using synthetic quartz, as in the first set of experiments, and varying amounts of ultrafine-grained quartz powder with a median grain diameter of $10 \mu \mathrm{m}$ made from Ottawa sand by the U.S. Silica Company. All samples were monitored from outside the vessel through the window using a long-working-dis- 


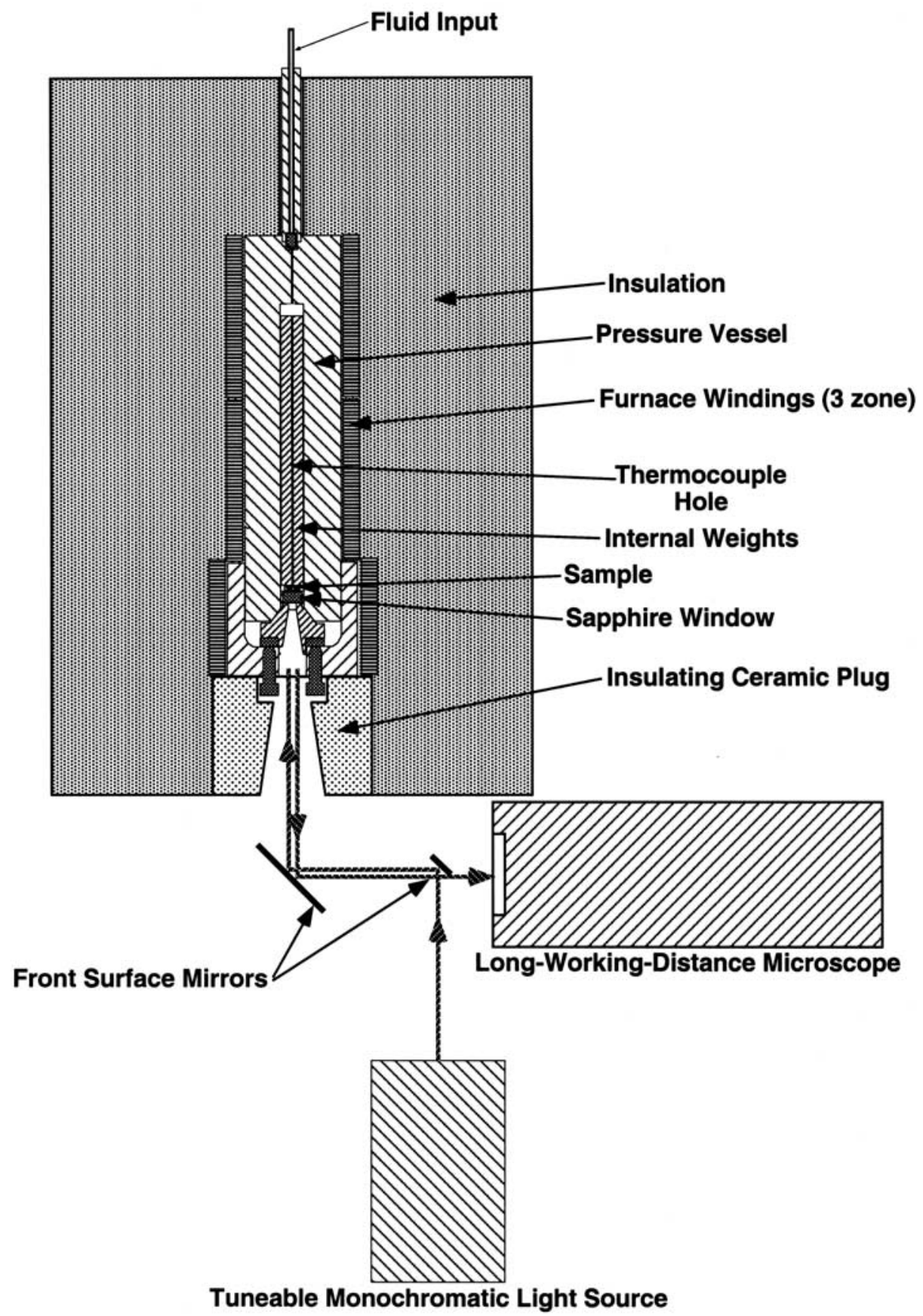

Figure 2. Schematic of experimental apparatus. The pressure vessel has a sapphire window in the base. Not to scale.

tance microscope equipped with a digital video camera. The camera was input to a video recorder that recorded the entire experiment. The camera was interfaced with a computer; digital images were periodically captured and used for quantitative determination of aperture and crack tip position using reflected light and interference fringes (see below). Temperature $\left( \pm 0.2^{\circ} \mathrm{C}\right)$ within the pressure vessel was measured with a thermocouple inserted through the highpressure port at the top of the vessel to within an inch of the sample. Fluid pressure ( \pm 2 bars) was measured with an in-line pressure transducer and a pressure gauge.
[6] For all experiments the final conditions were $530^{\circ} \mathrm{C}$ temperature and $150 \mathrm{MPa}$ water pressure. The samples were raised to these conditions from $22^{\circ} \mathrm{C}$ and $0.1 \mathrm{MPa}$ over $\sim 2.5$ hours. Temperature was raised from 22 to 100, from 100 to 300 , and from 300 to $530^{\circ} \mathrm{C}$ in three increments. Fluid pressure increased via thermal expansion over these increments but was manually reduced to keep pressure below a few tens of megapascals over the first two temperature increases and as necessary to keep pressure from greatly exceeding $100 \mathrm{MPa}$ during the final increment. Pressure was increased to $150 \mathrm{MPa}$ after temperature had 
Table 1. Fracture Closure Experiments

\begin{tabular}{|c|c|c|c|c|c|c|c|c|}
\hline Experiment & $\begin{array}{c}\text { Initial } \\
\text { Sample } \\
\text { Weight, g }\end{array}$ & $\begin{array}{l}\text { Additional } \\
\text { Quartz } \\
\text { Weight, g }\end{array}$ & $\begin{array}{c}\text { Additional Quartz } \\
\text { Powder } \\
\text { Weight, g }\end{array}$ & $\begin{array}{c}\text { Total Available } \\
\text { Surface Area, } \\
\mathrm{cm}^{2}\end{array}$ & $\begin{array}{c}\text { Residual } \\
\text { Fracture } \\
\text { Volume, \% }\end{array}$ & $\begin{array}{c}\text { Sample } \\
\text { Weight } \\
\text { Change, g }\end{array}$ & $\begin{array}{l}\text { Crack Length, } \\
\text { Tip to } \\
\text { Borehole, mm }\end{array}$ & $\begin{array}{c}\text { Crack Half } \\
\text { Aperture at } \\
\text { Borehole, mm }\end{array}$ \\
\hline qch 6 & 0.9228 & 3.9155 & 0 & 11.30 & $<28^{\mathrm{a}}$ & -0.0046 & 5.2 & 0.00028 \\
\hline qch 11 & 0.8043 & 3.8324 & 0 & 11.32 & $100^{\mathrm{b}}$ & -0.0034 & 5.5 & 0.0023 \\
\hline qch 12 & 0.8920 & 3.7964 & 0 & 11.32 & 21 & -0.0040 & 4.1 & 0.0012 \\
\hline qch 13 & 0.9536 & 3.7606 & 0.0572 & $1.02 \times 10^{3}$ & 47 & -0.0020 & 4.5 & 0.0024 \\
\hline qch 14 & 0.7119 & 3.7447 & 0.6130 & $1.09 \times 10^{4}$ & 28 & -0.0011 & 3.4 & 0.00047 \\
\hline qch 15 & 0.7304 & 3.7333 & 6.0144 & $1.07 \times 10^{5}$ & 56 & -0.0002 & 3.6 & 0.00048 \\
\hline qch 16 & 0.7195 & 0 & 0 & 11.32 & $100^{\mathrm{c}}$ & 0.0000 & 5.6 & 0.0010 \\
\hline
\end{tabular}

${ }^{\mathrm{a}}$ Initial maximum fracture width small enough that closure eliminated all interference fringes. In situ measurements require remaining fracture volume $<28 \%$. Estimates from the recovered sample suggest $\sim 10-15 \%$.

${ }^{\mathrm{b}}$ Silver wire lodged in the borehole was used as an artificial prop and prevented closure.

${ }^{\mathrm{c}}$ Annealed dry at $1 \mathrm{~atm}$.

stabilized at $\sim 530^{\circ} \mathrm{C}$. Experiments were quenched from run conditions by reducing the water pressure to atmospheric pressure over a few minutes and then allowing the vented vessel to cool naturally to room temperature.

[7] The following analysis and discussion use a number of symbols to represent the physical properties of the hydrothermal system; these symbols, their definitions, and their dimensions are listed in Table 2. Light reflected off the top and bottom surfaces of the fracture interferes and produces interference fringes that were used to measure the fracture aperture (Figures 1 and 3). Half-aperture $w$ associated with an interference minimum of order $o$ is

$$
w=\frac{o \lambda}{4 n}
$$

where $\lambda$ is the wavelength of light and $n$ is the refractive index of the fluid within the fracture [e.g., Rossi, 1965]. A similar equation specifies the aperture for interference maxima. The order number was determined by twice measuring the aperture of the same point on the fracture surface using two adjacent fringes, $m$ and $m+1$, yielding $m=\lambda_{1} /\left(\lambda_{1}-\lambda_{2}\right)$ by simultaneous solution of equation (1) [Hickman and Evans, 1987]. The refractive index, required for the solution of equation (1) for $w$, is

$$
n=\sqrt{\frac{2 R_{m}+V_{m}}{V_{m}-R_{m}}}
$$

where $V_{m}$ and $R_{m}$ are the molar volume and molar refractivity, respectively, of water [Atkins, 1982]. The temperature and pressure dependence of equation (2) is contained in $V_{m}$. Throughout we assume that $R_{m}$ and $n$ are frequency-independent (no dispersion), and we determine $R_{m}=3.68 \mathrm{~cm}^{3} / \mathrm{mol}$ from equation (2) using $n=1.333$ at room temperature and pressure. The molar volume of water was calculated using the relationship of Fournier and Potter [1982] and the tabulated data of Burnham et al. [1969]. Using equations (1) and (2) and the measured temperature, pressure, and interference patterns, $w$ can be determined as a function of position and time throughout the experiment.

\section{Observations}

[8] The initial normalized half aperture as a function of normalized distance from the fracture tip is similar for all fractures used in the study (Figure 4). Fracture length varies by a factor of $\sim 2$, and the measured maximum aperture varies by approximately an order of magnitude in the six fractures shown. The half-aperture distribution as a function of distance from the tip is empirically well described by a hyperbola:

$$
y=\frac{b}{a}\left[(x+a)^{2}-a^{2}\right]^{1 / 2},
$$

where $y=w / w_{b}$ is the half-aperture $w$ normalized by the half aperture at the borehole $w_{b}, x=l / l_{t b}$ is the distance from the tip $l$ normalized by the tip to borehole length $l_{t b}$, and $a$ and $b$ are constants. The half-aperture distribution is similar to that predicted by plane strain boundary element linear elastic calculations (see below).

[9] Upon heating and pressurization to run conditions, uniform fracture closure occurs (Figure 5a). This closure is distinctly a different process than "crack healing," which results from precipitation and infilling of cracks driven by gradients in surface curvature [Brantley et al., 1990]. In our experiments, profiles prior to heating $(\Delta t=0)$ and up to

\begin{tabular}{|c|c|c|c|}
\hline Symbol & Definition & Dimension & Equation \\
\hline$w$ & half aperture & $\mathrm{m}$ & (1) \\
\hline$o$ & order & dimensionless & (1) \\
\hline$\lambda$ & wavelength & $\mathrm{m}$ & (1) \\
\hline$n$ & refractive index & dimensionless & (1) \\
\hline$R_{m}$ & molar refractivity & $\mathrm{cm}^{3} / \mathrm{mol}$ & (2) \\
\hline$V_{m}$ & molar volume & $\mathrm{cm}^{3} / \mathrm{mol}$ & (2) \\
\hline$M$ & amount of fluid & mol & $\ldots$ \\
\hline$A_{t}$ & fluid-solid interfacial area & $\mathrm{m}^{2}$ & $\ldots$ \\
\hline$k_{+}$ & dissolution rate constant & $\mathrm{mol} / \mathrm{m}^{2} \mathrm{~s}$ & (5) \\
\hline$\Delta \mu$ & chemical potential & $\mathrm{J} / \mathrm{mol}$ & (4) \\
\hline$R$ & gas constant & $\mathrm{J} / \mathrm{mol}^{\circ} \mathrm{K}$ & (4) \\
\hline$T$ & temperature & ${ }^{\circ} \mathrm{K}$ & (4) \\
\hline$\Theta$ & solubility product & dimensionless & (4) \\
\hline$K$ & equilibrium constant & dimensionless & (4) \\
\hline$\Gamma_{s l}$ & solid-liquid surface energy & $\mathrm{J} / \mathrm{m}^{2}$ & (4) \\
\hline$\kappa_{0}$ & mean curvature & $1 / \mathrm{m}$ & (4) \\
\hline$\kappa_{c}$ & mean particle curvature & $1 / \mathrm{m}$ & (4) \\
\hline$\sigma_{n}^{c}$ & contact normal stress & $\mathrm{MPa}$ & (4) \\
\hline$m$ & amount of material dissolved at contact & $\mathrm{mol} / \mathrm{m}^{2}$ & (5) \\
\hline$t$ & time & $\mathrm{s}$ & (5) \\
\hline$C_{0}$ & starting concentration in mole fraction & dimensionless & (5) \\
\hline$C$ & concentration in mole fraction & dimensionless & (5) \\
\hline$L$ & closure & $\mathrm{m}$ & (6) \\
\hline$\rho$ & particle radius & $\mathrm{m}$ & (6) \\
\hline$s$ & crack stiffness & $\mathrm{N} / \mathrm{m}$ & (6) \\
\hline$D$ & diffusion coefficient & $\mathrm{m}^{2} / \mathrm{s}$ & (8) \\
\hline$\nabla \mu$ & chemical potential gradient & $\mathrm{J} / \mathrm{mol} \mathrm{m}$ & (8) \\
\hline$Q$ & activation energy & $\mathrm{J} / \mathrm{mol}$ & $\ldots$ \\
\hline
\end{tabular}
$\sim 200^{\circ} \mathrm{C}$ are nearly identical; slight differences may be in

Table 2. Symbols and Dimensions 


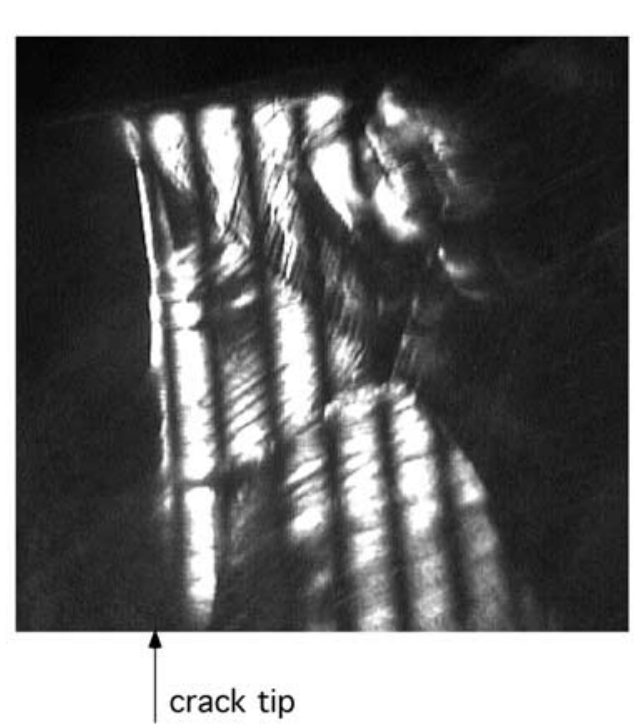

$$
\begin{aligned}
& \Delta t=01: 03: 00, T=247^{\circ} \mathrm{C}, \\
& P=16 \mathrm{MPa}
\end{aligned}
$$

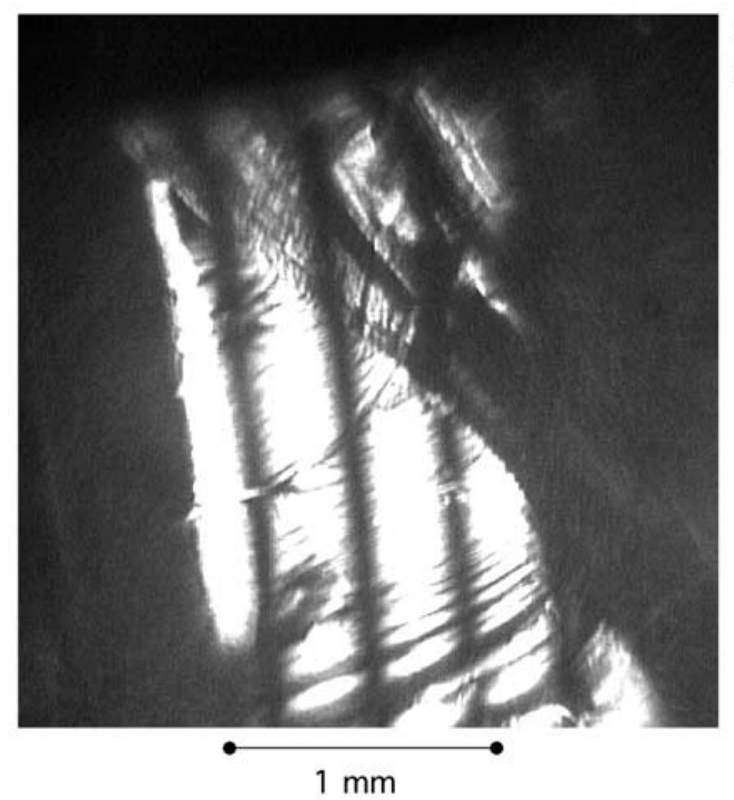

$\Delta \mathrm{t}=03: 09: 55, \mathrm{~T}=530^{\circ} \mathrm{C}$, $\mathrm{P}=150 \mathrm{MPa}$

Figure 3. Near-tip in situ micrograph of a fracture (qch 13) shown at two different times. Cartoon at right shows the orientation of the cracks within the two images on the left. (top) After 1 hour. Position of the crack tip is toward the left-hand side and is roughly vertical. Vertical band lines are interference fringes. (bottom) After 3 hours, there are fewer interference fringes, indicating that the fracture has closed; in this example, closure is $\sim 50 \%$. The scale is approximately the same as shown at the top.

part due to measurement error. As the experiment proceeds to temperatures near $300^{\circ} \mathrm{C}$ and pressures above $100 \mathrm{MPa}$, the fracture closes rapidly. As the fracture closes, resolution of the near-tip profile is lost for the thinnest fractures (Figure 5a). For wider cracks the profile is well resolved and data indicate that the fracture profile remains hyperbolic (Figure 5b). After the sample has reached the final temperature and pressure conditions the closure stops; profiles at large $\Delta t$ are indistinguishable from one another. The fracture does remain open with measurable aperture after closure occurs.

[10] Closure in these experiments occurs as the force that holds the fracture open is removed; thus understanding and extrapolating closure data is predicated on knowledge of what holds the fracture open initially. The measured fracture profiles differ significantly from conventional elliptical crack shapes (dotted curve, Figure 4a), which result from uniform normal stress on the fracture face provided by elevated fluid pressure within the fracture or from static differential stress. To infer the forces that hold open the fractures in this study, plane-strain cracks with geometry similar to the experimental samples were calculated numerically with the linear elastic boundary element implementation of Crouch and Starfield [1990]. The geometry used is a single-ended crack emanating from a cylindrical borehole within a finite sample, propped open by a line load within the fracture on the opposite side of the borehole from the tip (Figure $4 \mathrm{~b}$ ). In the experiments, analogous propping is 

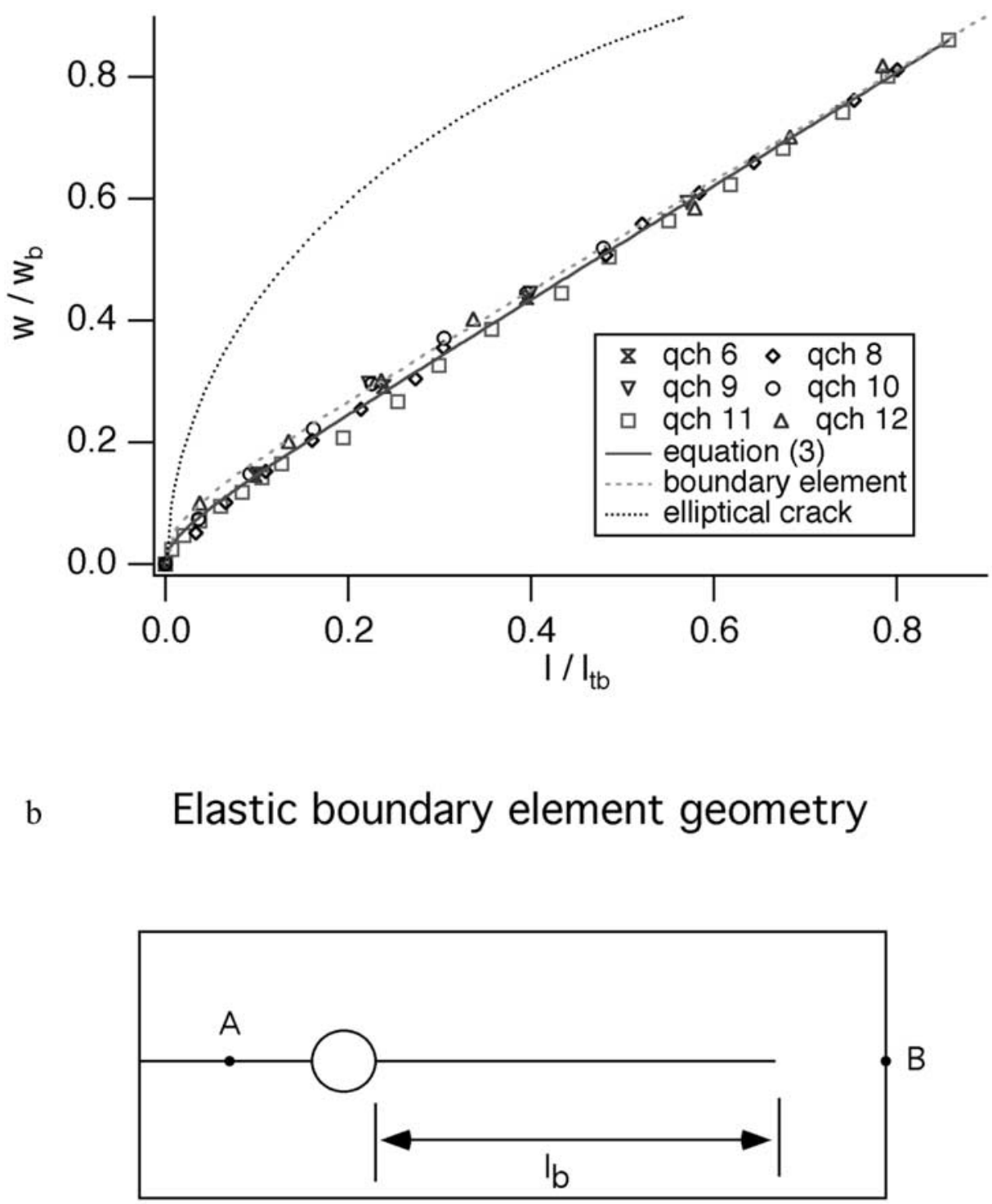

Figure 4. (a) Normalized half aperture as a function of normalized distance from the fracture tip for selected representative fractures used in this and a companion crack healing study by Beeler and Hickman [1996]. (b) Geometry of boundary element calculation intended to represent the experimental geometry. The boundary conditions are point A, normal displacement specified and zero shear stress; and point B, zero shear and normal displacement. All other points on the surface are shear and normal stressfree. Results of calculation are shown as the dashed curve in Figure 4a. In the calculation the tip to borehole distance is $3.3 \mathrm{~mm}$, the borehole diameter is $1.4 \mathrm{~mm}$, and the borehole to prism end distance is $3.3 \mathrm{~mm}$. The prop is located halfway between the borehole and the prism end at point A.

liable to be more irregular, resulting from debris generated during fracture or from roughness on the fracture surface. A calculated profile is shown in Figure $4 \mathrm{a}$ and quite closely resembles the profile of the experimental fractures. If the size of the prop is reduced, the normalized shape of the boundary element-calculated profile remains the same. Because the closure measurements show that the aperture distribution remains hyperbolic (Figure 5b), the elastic calculations suggest simply that closure occurs as the size of this prop is gradually reduced at elevated temperature and pressure. Thus the initial profiles of experimental fractures and the fracture shape during closure are consistent with the predictions of linear elasticity if the fracture is held open by a prop located a large distance from the fracture tip. 


\section{a}

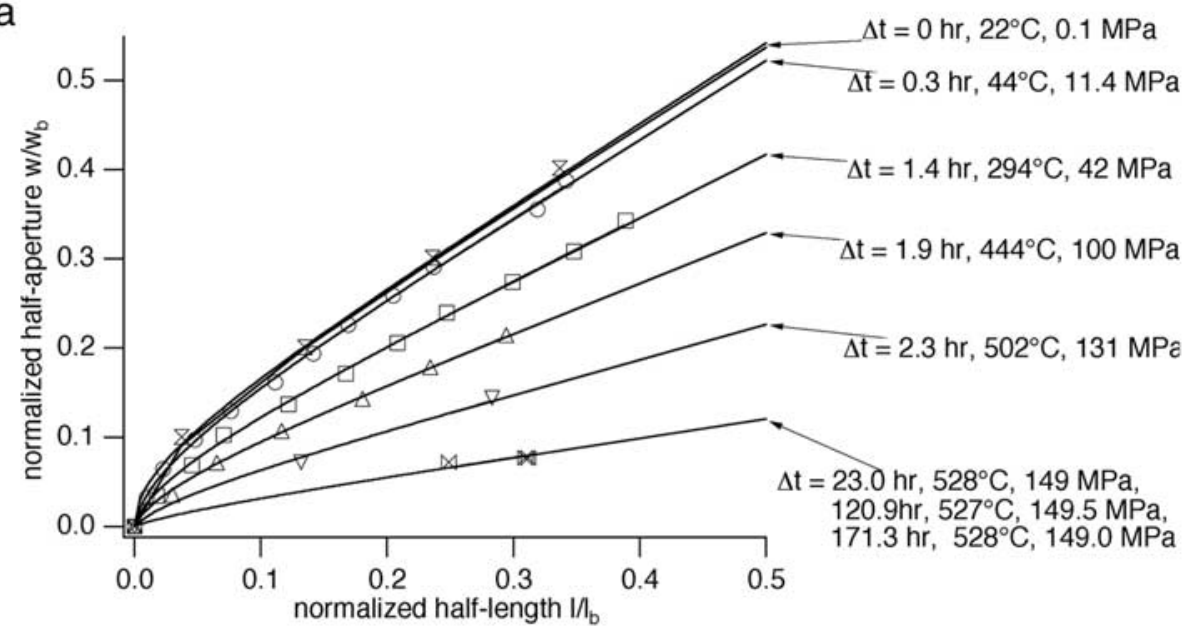

b

\section{Initial and final profile}

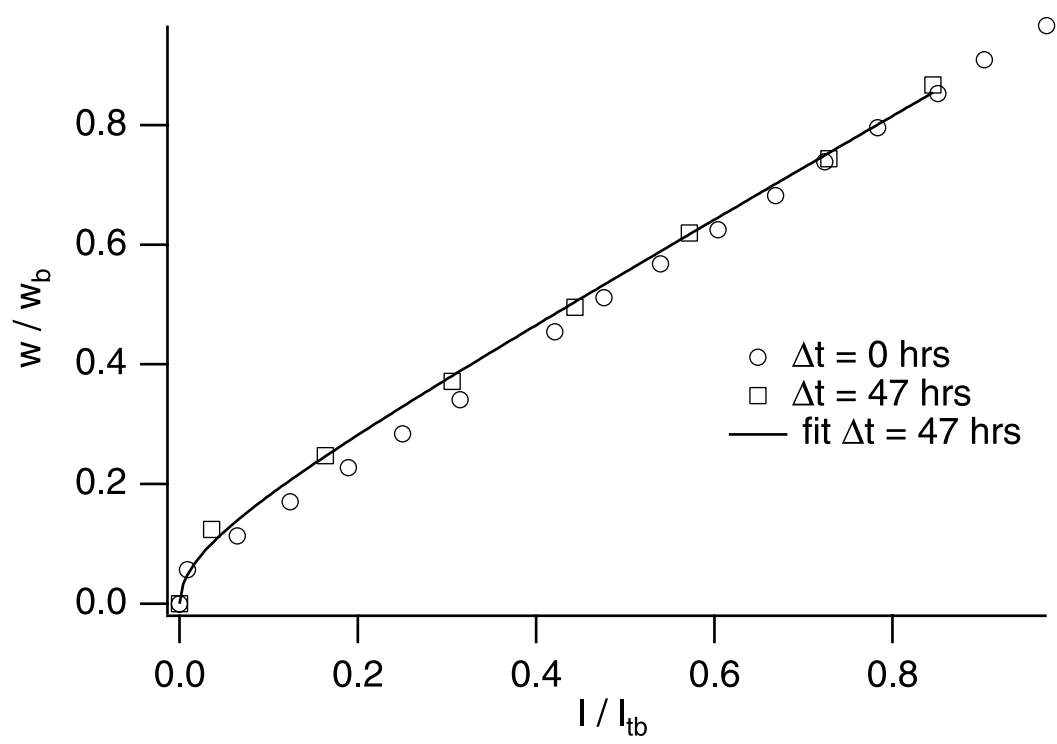

Figure 5. Time-dependent closure. (a) Data for fracture aperture as a function of time for a single experiment (qch 12) shown at eight different times. The time, temperature, and pressure for each profile are shown to the right. Half aperture is normalized for all data using the value of half aperture at the borehole measured at $\Delta t=0$. The lines are least squares fits to the data using equation (3). Fits to data at $\Delta t>0$ have $a$ fixed to the value from the fit $\Delta t=0$. The resolution of the crack profile is lost at long times because of the reduction in the number of interference fringes. (b) Data for a wider crack normalized to emphasize final fracture shape. As shown here (qch 13), the stable profile after 47 hours is approximately hyperbolic. Half aperture for $\Delta t=47$ hours is normalized using the value of half aperture at the borehole at $\Delta t=47$ hours.

[11] Recovered samples show features of the partially closed fracture related to propping: regions of asperity contact and visible healed subsidiary microfractures (Figure 6). Closure stops in the experiments at a time when stored elastic stress is effectively zero, yet the aperture is nonzero; therefore permanent inelastic deformation occurs either during the fracture process or during the experiment. A likely cause for this inelastic deformation is subsidiary microcracks, which are seen in the recovered samples (Figure 6). At high temperature, thin microcracks in quartz undergo rapid crack healing [Smith and Evans, 1984; Brantley, 1992] such that the main fracture in our experiments could be held open by healed-in shear offsets on the subsidiary microcracks. The partially closed main fracture is further mechanically sup- 


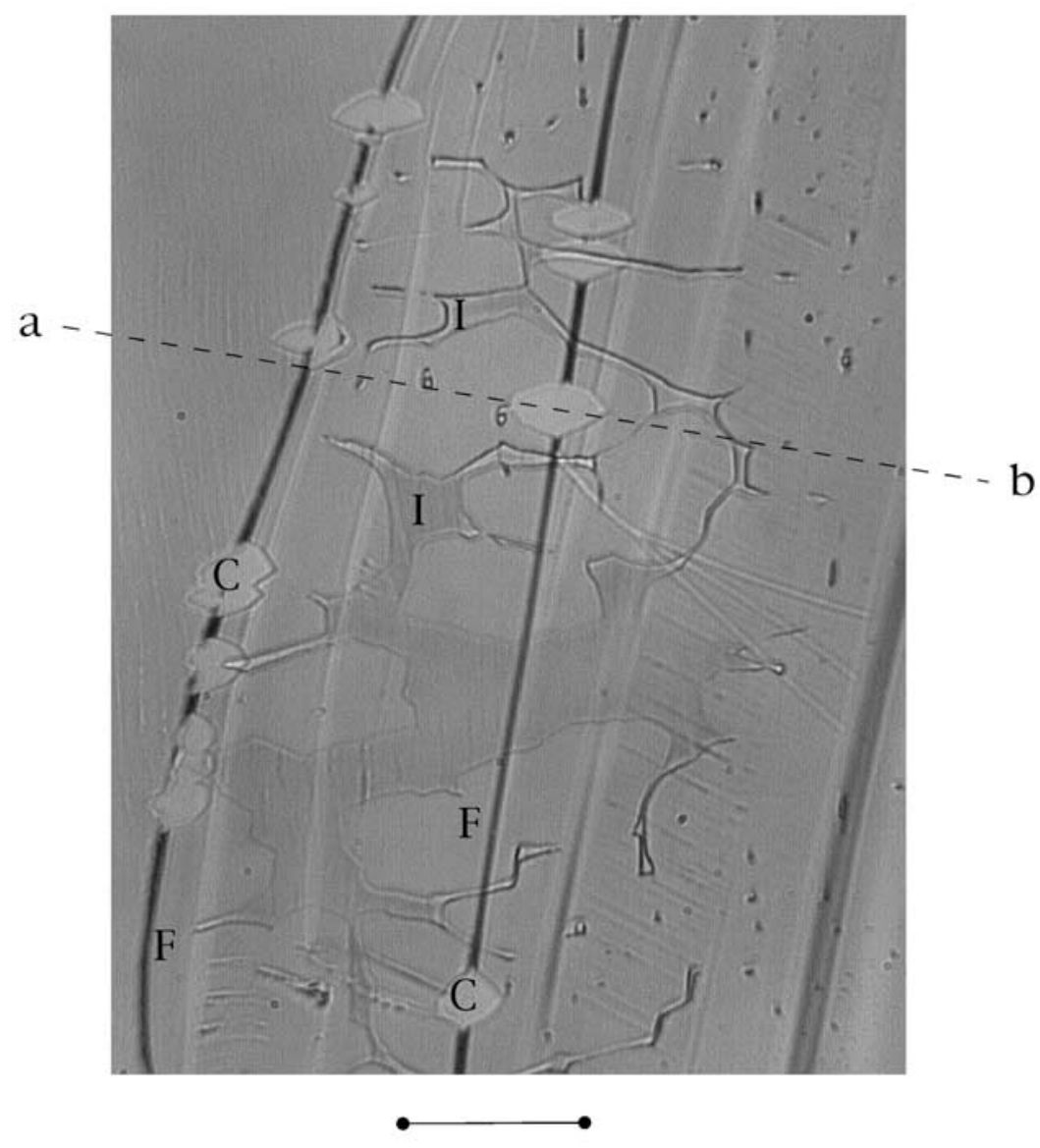

$0.1 \mathrm{~mm}$

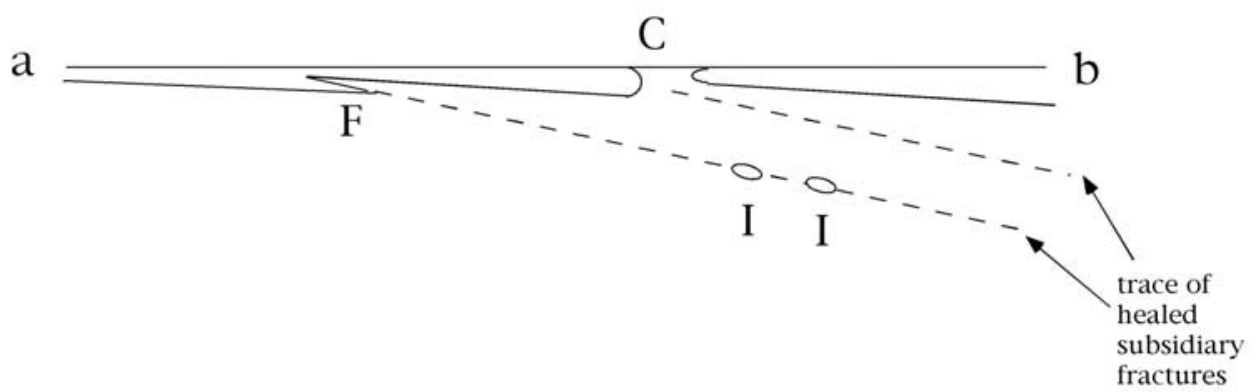

Figure 6. (top) Optical photomicrograph of a portion of the recovered fracture surface, looking down on the fracture through the polished $\left(\begin{array}{lll}10 & 1 & 1\end{array}\right)$ face. Two subsidiary fractures are shown whose intersections with the main fracture are dark linear features $(F)$. The subsidiary fractures, which intersect the main fracture at a low angle, contain fluid inclusions $(I)$. The majority of subsidiary fracture surface has healed. The labeled inclusions are large, and many smaller ones are also visible. Also shown are asperity contacts $(C)$ between the sides of the main fracture. These obliterate the dark trace of the subsidiary fractures and thus occur along the intersection of the subsidiary and main fractures. Shear offsets on the subsidiary fracture provide a raised surface on the main fracture, which makes contact as the fracture closes. Another interesting observation is that large conjoined asperity contacts are seen surrounding the fluid inclusions on the subsidiary fracture; the coalescence of these asperity contacts is a prime contributor to healing these subsidiary fractures. A schematic cross section from $a$ to $b$ that shows the relative positions of contacts, inclusions, and subsidiary fractures is below the photomicrograph.

ported by regions of contact between opposing sides of the fracture (Figure 6); these can form at the intersection of the subsidiary microcracks and the main fracture if there is sufficient shear offset on the subsidiary fracture.
[12] To insure that the observed time-dependent closure does not result from solid-state creep activated at high temperature, a control experiment was conducted. The sample was raised to $530^{\circ} \mathrm{C}$ in air and annealed for 
a

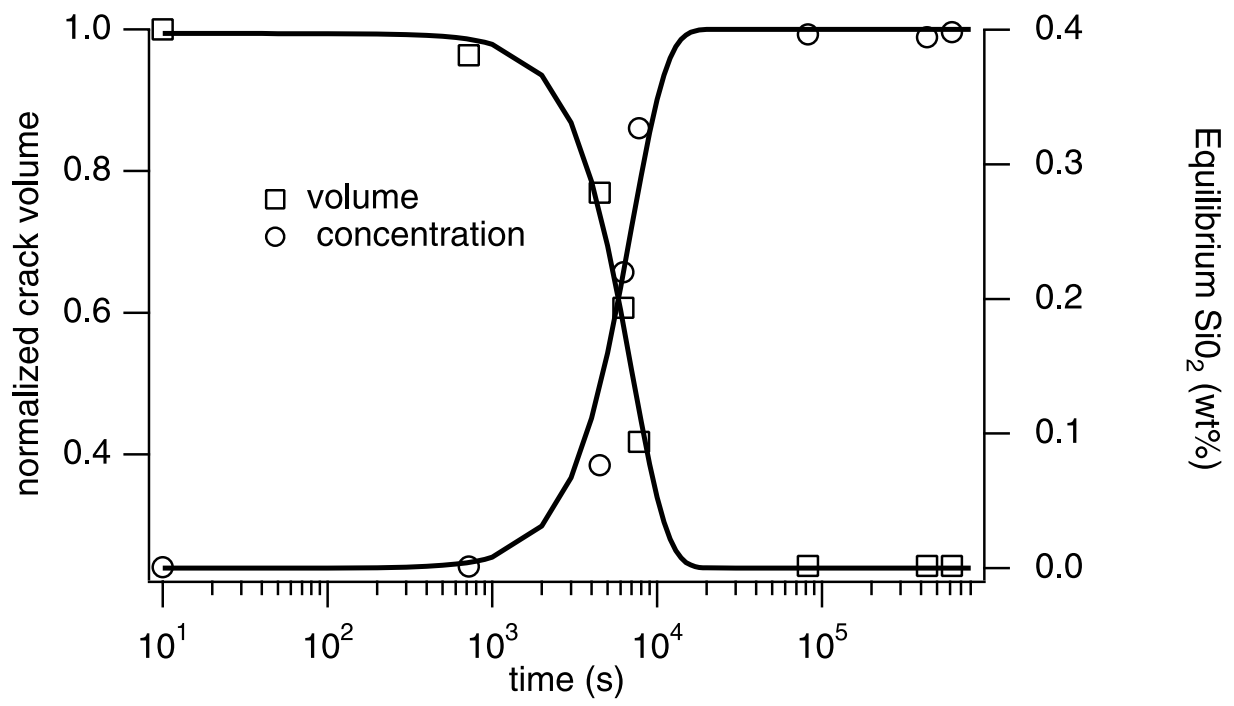

b

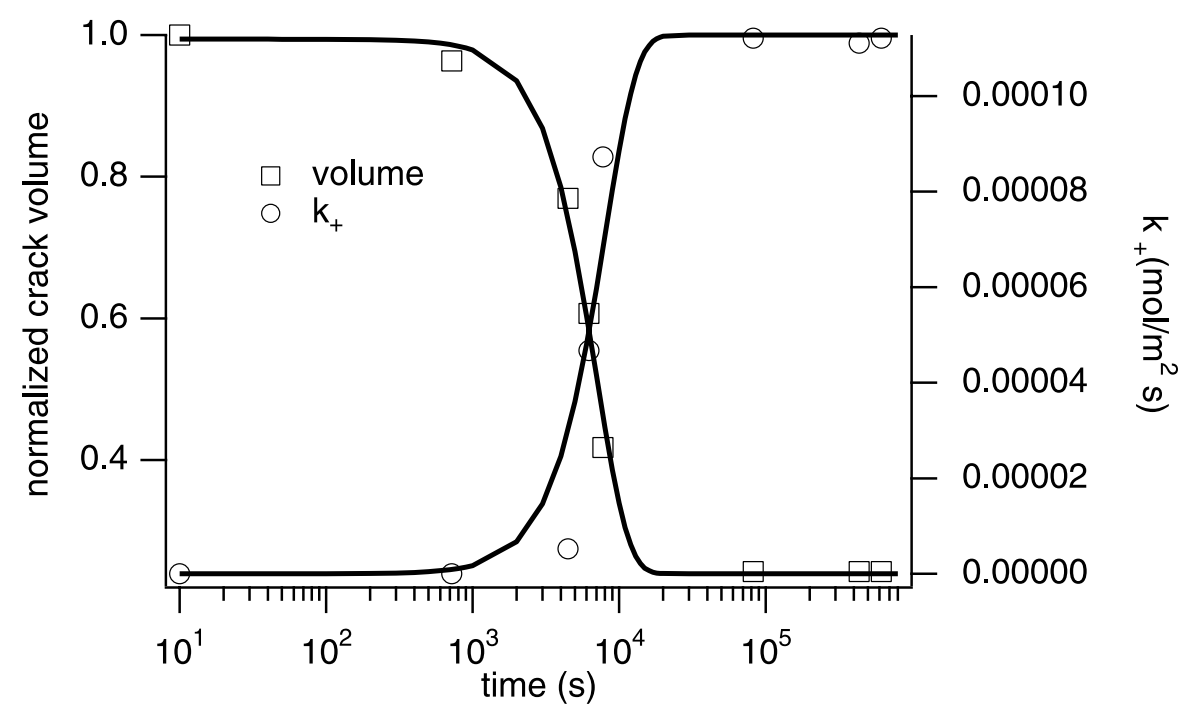

Figure 7. (a) Normalized crack volume percent and equilibrium concentration of silica in solution versus time for a single experiment. (b) Normalized crack volume percent and dissolution rate constant of silica versus time for a single experiment. The rate constant is calculated from the relationship of Rimstidt and Barnes [1980].

24 hours. No closure occurred. This result and the variation of fracture volume with the equilibrium concentration of silica in solution during the wet experiments (Figure 7a) suggest that closure results from dissolution of the prop; rapid closure coincides with rapid changes in silica concentration. Crack volume percent was calculated assuming the fracture profile remains hyperbolic at all times. Data were fit using equation (3) and the fracture volume, which is proportional to fracture cross-sectional area $A$. $A$ was determined from the integral of equation (3) evaluated from 0 to 1 :

$$
A=\frac{b}{a}\left\{\frac{1+a}{2}\left[(x+a)^{2}-a^{2}\right]^{1 / 2}-\frac{a^{2}}{2} \cosh ^{-1}\left(\frac{1+a}{2}\right)\right\} .
$$

Equilibrium concentrations were calculated from the relationship of Fournier and Potter [1982], using measured values of pressure and temperature, and the tabulated data of Burnham et al. [1969]. However, quantifying the relationship between closure and silica concentration is complicated by nonequilibrium conditions. The actual concentration will lag behind the equilibrium concentration in time as an exponential function whose characteristic time is $M / A_{t} k_{+}$, where $k_{+}$is the dissolution rate constant for the reaction $\left(\mathrm{mol} / \mathrm{m}^{2} \mathrm{~s}\right), M$ is the amount of fluid $(\mathrm{mol})$, and $A_{t}$ is the fluid-solid interfacial area [Rimstidt and Barnes, 1980; Dove and Crerar, 1990]. The rate constant for silica dissolution has not been measured experimentally for temperatures greater than $300^{\circ} \mathrm{C}$, so we have extrapolated the lower-temperature data. For the temperature and 
pressure path of our experiments, $k_{+}$covaries with closure in a manner similar to the equilibrium concentration (Figure 7b).

\subsection{Chemical Driving Force for Closure}

[13] The net driving force for dissolution of the prop, written in terms of the chemical potential, is

$$
\Delta \mu=R T \ln \frac{\theta}{K}+\left(\kappa_{0}-\kappa_{c}\right) \Gamma_{s l} V_{m}+\sigma_{n}^{c} V_{m}
$$

The first term represents the driving force for bringing an undersaturated solution to saturation [e.g., Stumm and Morgan, 1981], $R$ is the gas constant, $T$ is temperature $(\mathrm{K}), \theta$ is the solubility product, and $K$ is the equilibrium constant. For solutions at low solute concentration, as is probably appropriate for silica in the shallow crust, the ratio $\theta / K$ is equivalent to the degree of saturation of the solution. The second term, the Gibbs-Thompson equation, represents the additional driving force for dissolution of small particles, sometimes called the coarsing potential (Ostwald ripening [Ostwald, 1895]), where $\kappa_{0}$ is the average curvature of all the solid-liquid surfaces in the system, $\kappa_{c}$ is the mean curvature of the propping particle, $\Gamma_{s l}$ is the solid-liquid surface energy, and $V_{m}$ is the molar volume of the solid [e.g., Blakely, 1973]. The third term is the driving force for pressure solution of the prop, where $\sigma_{n}^{c}$ is the effective normal stress at the contact between the prop and the fracture face (i.e., normal stress minus fluid pressure) [Robin, 1978].

[14] Whether the rate of closure of similar fractures in the Earth's crust resembles that in our experiments depends critically on which of the terms in equation (4) is dominant. If the first term is dominant, then significant fracture closure in the Earth would only be expected in instances where the solution is significantly undersaturated with respect to the propping material, for example, following an earthquake where frictional heating had occurred and the fluid had not yet equilibrated with the surroundings. If the second term is the principal driving force, then significant closure would only be expected in cases where the propping particle was below a critical size; in this case the maximum fracture opening would be small. However, if the driving force is pressure solution via high normal stress at the contact of the prop, then significant time-dependent closure would be expected in any case where $\sigma_{n}^{c}>0$. Note that in the Earth, $\sigma_{n}^{c}$ will have contributions from the macroscopic fracture normal stress and from stored elastic energy surrounding the fracture. In our experiments the latter contribution provides a significant stress on the prop even though it is under macroscopically hydrostatic stress.

[15] The expected sizes of the first two terms in equation (4) can be calculated from the fracture dimensions and known constants. For instance, if there is no dissolution of quartz as temperature and pressure are raised to $530^{\circ} \mathrm{C}$ and $150 \mathrm{MPa}$, respectively, the term $R T \ln \theta / K$ has the value of $42 \mathrm{~kJ} / \mathrm{mol}$. This maximum is an overestimate of the degree of saturation because at temperatures between 200 and $530^{\circ} \mathrm{C}$, occasional leaks of hydrothermal fluid occur around the vessel window and these leaks generate silica deposits on the outside of the vessel. Thus we know there is significant silica in solution at temper- atures as low as $200^{\circ} \mathrm{C}$. However, for the purposes of discussion, $42 \mathrm{~kJ} / \mathrm{mol}$ is an upper bound. For the second term, assuming a spherical propping particle with radius equal to the maximum half aperture and $\kappa_{0}=0$ (flat surface), maximum half apertures of order 1.0-0.1 $\mu \mathrm{m}$ yield a contribution on the order of $20-300 \mathrm{~J} / \mathrm{mol}$, calculated using dry surface energy data from Brace and Walsh [1962] at room temperature. Solid liquid interfacial energy is expected to be smaller and may decrease as a function of temperature [e.g., Hay and Evans, 1988]; thus this range is an upper bound on the contribution from the second term in equation (4). Therefore Ostwald ripening likely does not play an important role in closure. The expected size of the third term can be deduced from estimated contact stresses from our boundary element elastic calculations. These calculations indicate that contact stresses are on the order of the indentation yield strength of quartz (e.g., 10.0 GPa [Dieterich and Kilgore, 1996, and references therein]). If we assume stresses of this size, the stress-induced driving force is in the range of $\sim 230 \mathrm{~kJ} /$ mol. Thus fracture closure appears to result primarily from pressure solution but with possible secondary contributions from prop dissolution or coarsening. These results indicate that time-dependent closure will occur for all fractures where the prop is soluble, not just those in undersaturated solutions or with small props.

[16] To confirm that stress-induced closure is dominant, we conducted an additional suite of experiments where the first term in equation (4) was systematically varied by adding varying amounts of crushed fine-grained quartz sand (Table 1). The fine-grained quartz increases the available surface area for dissolution, and because the dissolution reaction rate is proportional to the amount of available reactive surface area [Rimstidt and Barnes, 1980], equilibrium is reached more rapidly. Speeding up the reaction rate reduces the size of the first term in equation (4) at all times by making $\theta / K$ more nearly 1 . Available surface area was calculated using the measured mass, the known grain size distribution (particle size analysis provided by U.S. Silica Company, Ottawa, Illinois), an empirical relationship for specific surface area $S_{w}=C_{1} / \rho_{s} d$ ( $\rho$ is density and $d$ is grain diameter), and the data from crushed St. Peter sand of Leamnson et al. [1969]. The constant $C_{1}$ is 21.5 for Leamnson et al.'s data.

[17] The additional powdered quartz also somewhat decreases the size of the second term in equation (4) by increasing the mean surface curvature $\kappa_{0}$ of the system. Experiments were conducted where the amount of available surface area was increased by factors of approximately 90, 968, and 9502 over the available surface area in the first set of experiments. The mean surface curvatures were consequently increased from near zero (flat surface) to the mean curvature of the quartz powder $(\sim 15 / \mu \mathrm{m})$. This reduction in curvature will reduce the second term in equation (4) by about $10 \%$ if the prop radius is $1.0 \mu \mathrm{m}$ but will not significantly alter the size of the second term in equation (4) if the propping particle radius is as small as $0.1 \mu \mathrm{m}$.

[18] A measurable systematic effect of the additional silica is to reduce the amount of sample weight loss during the experiment (Figure 8). Within the measurement precision $( \pm 0.0004 \mathrm{~g})$, no weight loss occurred in the experiment at the largest available surface area (qch 15, Table 1), 


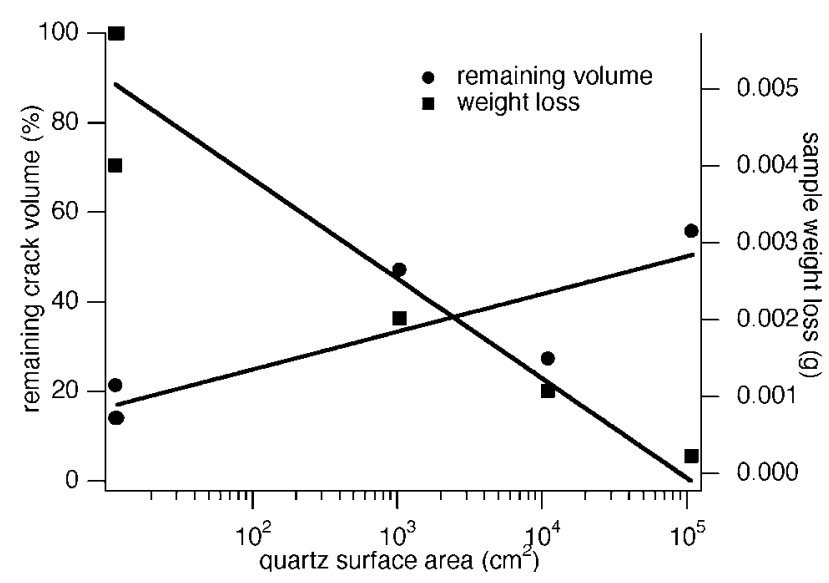

Figure 8. Sample weight loss over the duration of the experiment and crack volume remaining at the end of the experiment, as a percent, as a function of estimated quartz surface area for experiments with varying amounts of added fine-grained quartz powder.

indicating that the sample was at or near local equilibrium throughout the experiment, i.e., $\theta / K \approx 1$ in equation (4). In this experiment the first term in equation (4) is negligible. Still, fracture closure is observed in this and all other experiments with additional fine-grained quartz (Figure 8). The data suggest a decrease in the amount of closure as the amount of available surface area is increased, consistent with a reduction in the contribution of the first term in equation (4). However, there is scatter in the data, and the trend may in part indicate sample to sample variability (for example, variability in the crack stiffness). In either case, significant fracture closure occurs even at near-equilibrium conditions, suggesting that at the very least, a large part of the time-dependent closure results from pressure solutionlike removal of the prop.

\subsection{Rate of Closure}

[19] According to our observations, rapid fracture closure can occur if $\sigma_{n}^{c}>0$ and solubility is high. Fluid within the fractures will be expelled during closure if the fracture is open to the surroundings; alternatively, if the fracture porosity is isolated, fluid pressure will increase. A number of recent theoretical studies in which earthquake rupture initiates because of compaction-induced pore pressure increase [Sleep and Blanpied, 1994; Lockner and Byerlee, 1995] emphasize the potential importance of coupled changes in pore fluid pressure, pore volume, and fault strength during the earthquake cycle. Because earthquake rupture generates fracture porosity, the rate at which fractures and pore space close following rupture is also a fundamental control on the rate of intrinsic fault strength recovery between earthquakes. Similarly, temporal variation of fault zone permeability, seismic velocities, and other physical properties that depend on fracture volume and geometry are expected. For these reasons we develop some simple, testable rate equations for porosity reduction via fracture closure.

[20] If we assume that transport of silica within solution in the experiments is rapid with respect to the rate of dissolution, the rate of removal of material from the prop- fracture wall contact is controlled by the dissolution reaction rate

$$
\frac{d m}{d t}=k_{+}\left(1-\frac{C_{0}}{C}\right),
$$

where material $m\left(\mathrm{~mol} / \mathrm{m}^{2}\right)$ added to the solution is taken as positive, $k_{+}$has dimensions $\mathrm{mol} / \mathrm{m}^{2} \mathrm{~s}, C$ is the concentration of silica (mole fraction, dimensionless) at the contact, and $C_{0}$ is the equilibrium concentration of silica in the bulk solution adjacent to the contact [Dove and Crerar, 1990]. Using a spherical prop (see Appendix A) and assuming that the chemical potential is given by the last term in equation (4), we find that the reduction in crack half aperture, the closure $L$, varies with time as

$$
\frac{d L}{d t}=\frac{d\left(w_{o}-w\right)}{d t} \approx \frac{k_{+} V_{m}^{2} s(\rho-L)}{R T \pi\left[\rho^{2}-(\rho-L)^{2}\right]}
$$

where $\rho$ is the initial radius of the prop, $w_{0}$ and $w$ are the starting half aperture and half aperture at the prop, respectively, and $s$ is the crack stiffness $(\mathrm{N} / \mathrm{m})$. Note that we have assumed that only the prop dissolves; this is an arbitrary assumption to simplify the geometry. In equation (6) the driving force for crack closure is stored elastic energy whose magnitude is related to the elastic crack stiffness $s$ and the fracture at half aperture the prop $(\rho-L)$. Assuming constant temperature and a starting value $L=0$, the solution to equation (6) is

$$
L^{2}-\rho L-\rho^{2} \ln (\rho-L)+\rho^{2} \ln (\rho)=\frac{s k_{+} V_{m}^{2} t}{\pi R T} .
$$

With equation (7), $L$ increases rapidly at small elapsed time, but rapid closure is predicted to start sooner than observed (Figure A2). Although high stress at the prop for short elapsed time may greatly enhance prop solubility, dissolution rate depends also on the reaction rate constant, which is known to increase rapidly with increasing temperature [Rimstidt and Barnes, 1981]. That $k_{+}$is not constant in the experiments qualitatively explains the difference between equation (7) and the observations. In the experiments, closure occurs as the pressure and temperature are increasing, so $C_{0}, k_{+}$, and $C$ in equation (5) increase in concert. However, because values of $k_{+}$and $C$ appropriate for our experiments are not well known, we are not able to solve equation (6) for $L$ accounting for time-dependent changes in concentration and the rate constant.

[21] If the removal of material at the prop is limited by the rate of diffusion, then from Fick's first law,

$$
\frac{d m}{d t}=-\frac{D C_{0} \nabla \mu}{V_{m} R T},
$$

where $m$ has the same dimensions as in equation (5), $D$ is the diffusion coefficient $\left(\mathrm{m}^{2} / \mathrm{s}\right)$, and $\nabla \mu$ is the chemical potential gradient $(\mathrm{J} / \mathrm{mol} \mathrm{m})$ [e.g., Hickman and Evans, 1992]. Evaluating equation (8), assuming a spherical prop (see Appendix A) and that the chemical potential is given by the last term in equation (4), leads to the closure rate

$$
\frac{d L}{d t}=\frac{d m}{d t} V_{m}=\frac{2 s D C_{0} V_{m}(\rho-L)}{\pi R T\left[\rho^{2}-(\rho-L)^{2}\right]^{3 / 2}}
$$




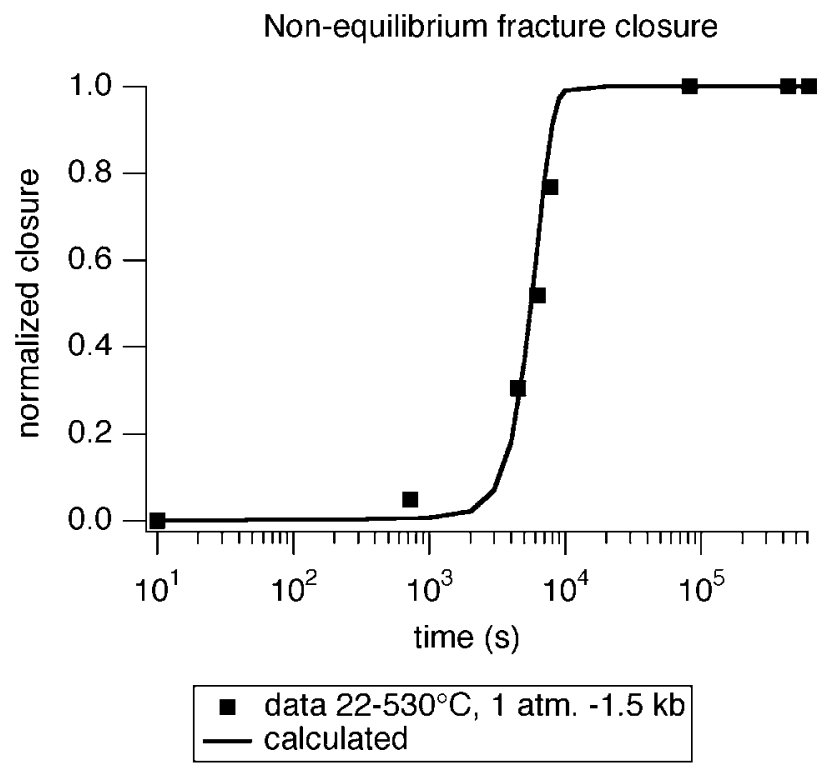

Figure 9. Comparison of fracture closure data to nonequilibrium simulation using the diffusion rate limited model equation (8) and temperature-dependent $D$ and $C_{0}$.

(see Appendix A). The solution of equation (9) at constant temperature, assuming that the starting value of $L=0$, is

$$
\begin{gathered}
-\frac{1}{3} \cos ^{3}\left(\sin ^{-1} \frac{\rho-L}{\rho}\right)-\cos \left(\sin ^{-1} \frac{\rho-L}{\rho}\right)-\ln \mid \csc \left(\sin ^{-1} \frac{\rho-L}{\rho}\right) \\
+\cot \left(\sin ^{-1} \frac{\rho-L}{\rho}\right) \mid=\frac{2 s D C_{0} V_{m} t}{\pi R T} .
\end{gathered}
$$

The temporal variation of closure predicted by equation (10) is very similar to that of equation (7), and the predicted rapid closure occurs sooner than observed (Figure A2).

[22] Since temperatures and pressures were increasing during our experiments, we also incorporated the known temperature and pressure dependencies of $D$ and $C_{0}$ into equation (8) to see if the resulting solution provides a better fit to the observations. We have solved equation (9) numerically using temperatures and pressures measured during a single experiment, $C_{0}$ calculated as a function of $T$ and $P$ from the expression of Fournier and Potter [1982] and the data of Burnham et al. [1969], and $D$ calculated as a function of $T$ from the Arrhenius equation, $D_{o}=\exp -$ $Q / R T$, where $Q=25 \mathrm{~kJ} / \mathrm{mol}$ and $D_{o}=9.37 \times 10^{-7} \mathrm{~m}^{2} / \mathrm{s}$ (consistent with the value of $D$ from Ildefonse and Gabis $[1976]$ at $\left.550^{\circ} \mathrm{C}\right)$. Because $s$ is constant but not well known, we have treated it as a free parameter. This equation fits the data well (Figure 9). This simple but quantitative pressure solution model for fracture closure under nonequilibrium conditions is consistent with all aspects of the data.

\section{Discussion}

[23] Additional evidence of rapid porosity decrease due to fracture closure is reported by Moore et al. [1994]. In that study, permeability of intact Westerly granite decreases exponentially with time at $300-500^{\circ} \mathrm{C}$. These samples are surface derived, and small shear offsets and props left from differential weathering make fractures difficult to close
[Morrow and Lockner, 1994], similar to the propped fractures in our study. Moore et al.'s study was conducted at constant confining pressure of $150 \mathrm{MPa}$ and pore fluid pressure of $100 \mathrm{MPa}$; thus the effective stress $\sigma_{e}=50 \mathrm{MPa}$ and $\sigma_{n}^{c}>0$. Our interpretation of crack closure is identical to Moore et al.'s: At elevated temperatures the mismatched points of asperity contacts and props become more readily soluble, leading to rapid closure and associated permeability loss over the first $1-2$ days at $300-500^{\circ} \mathrm{C}$ [Moore et al., 1994]. This transient regime of porosity and permeability reduction is distinct from long-term changes that are approximately logarithmic in time and are attributed to crack healing [Moore et al., 1994]. In some experiments the permeability reduction resulting from the transient closure regime exceeds the longterm changes over the duration of the experiments $(20-$ 50 days), particularly at lower temperatures.

\subsection{Implications of Fracture Closure for Interseismic Fault Properties}

[24] Qualitative arguments for large and rapid fault strengthening following earthquakes [e.g., Nadeau and Johnson, 1998; Sammis et al., 1999] are based on hydrothermal crack healing experiments conducted on single crystals of quartz [Shelton and Orville, 1980; Smith and Evans, 1984; Brantley et al., 1990; Brantley, 1992]. These experiments, which are carried out under temperature, water pressure, and loading conditions similar to those used in our study, show rapid healing of grain-scale microcracks at temperatures of $400^{\circ} \mathrm{C}$ and greater. However, fracture apertures during these crack-healing experiments were only indirectly inferred [e.g., Brantley et al., 1990], while healing rates of intercrystalline and intracrystalline cracks are known to be very strongly dependent on aperture [Hickman and Evans, 1986, 1992]. Although measurements of fracture aperture are critical to extrapolating laboratory crack healing rates to natural fault zones, our results show that fracture closure is likely to occur during the initial stages of these experiments; thus fracture aperture should be measured in situ, after fracture closure has occurred but before healing. An additional consideration in extrapolating laboratory crack-healing data acquired under hydrostatic loading conditions is that naturally produced dilatant cracks may be under significant applied effective normal stress; thus crack healing rates in the Earth may be much faster than observed in experiments if crack closure driven by macroscopic stresses reduces crack aperture prior to or during healing.

[25] Fractures of the type described in this study may be common in seismic crustal faults. Certainly, healed cracks are pervasive in exhumed seismogenic fault zones [Chester et al., 1993; Bruhn et al., 1994], and many of these healed fractures contain fluid inclusions formed at hydrostatic pore fluid pressure [Parry and Bruhn, 1990], in other words, at conditions where the macroscopic fracture normal stress $\sigma_{n}$ is likely to exceed $P^{f}$, requiring $\sigma_{n}^{c}>0$. Pervasive closure of such fractures would occur if the stress field during fracture formation is different than the subsequent static stress field. Possible mechanisms active during the seismic cycle that generate fractures of this type include hydrofracture, dynamic stress change, thermal stresses from frictional heating, and high local static differential stress prior to stress drop [e.g., Chester and Chester, 2000]. Observational evidence of rapid fault normal compaction following the 
Landers earthquake [Massonnet et al., 1996] and timedependent increases in seismic velocity following Landers [Li et al., 1998a, 1998b] are qualitatively consistent with our interpretation of the fracture closure observed in our experiments. Changes in seismic velocity due to fracture closure would be accompanied by large changes in fault zone permeability $k$ due to the strong dependence of permeability on fracture porosity $\phi$, e.g., $k \propto \phi^{3}[$ Walsh and Brace, 1984]. Thus, on the basis of our observations of rapid fracture closure we expect large and rapid changes in postseismic fault zone permeability. Such changes may be responsible for sealing fault zones with respect to the surrounding country rock, allowing elevated fluid pressure to build up in the fault core [Rice, 1992].

[26] Another reason that fracture porosity, as opposed to pores with more spherical shape, may be of interest in studies of large earthquakes at elevated fluid pressure is the relation between porosity reduction and the fault zone stress. Closure of equidimensional pores requires deformation of the surroundings (for example, via dislocation creep or pressure solution, which are driven by differential stress). Within a fault zone with nonzero strength subjected to increasing differential stress, ductile deformation that closes these pores leads to both shear and normal strains [e.g., Sleep and Blanpied, 1992]. Any shear strain that occurs in this situation is aseismic and relaxes the driving stress, reducing the seismic potential. As a result, model faults whose porosity is dominated by pores rather than fractures deform predominantly by aseismic creep [Sleep and Blanpied, 1992]. In contrast, closure of in-plane or subparallel fractures within a fault zone occurs with little or no aseismic shear strain and can raise fluid pressure at little cost to the driving stress for subsequent seismic failure.

\subsection{Limitations of the Experimental Observations}

[27] While closure is observed for all of the fractures subject to temperatures and pressures above $300^{\circ} \mathrm{C}$ and $100 \mathrm{MPa}$, respectively, the quantitative data on the rate of closure is limited. The fractures used had different lengths and starting apertures (Table 1); thus the driving stress is different in all cases and the closure rate would not be expected to be reproduced very exactly from experiment to experiment. Furthermore, the temperature and pressure time histories are different from one experiment to the next. Thus, in practice, the data cannot be used to show the degree of reproducibility or to constrain a causal relationship between stored elastic energy and the rate of closure. An additional complication is that the cracks with the smallest starting aperture closed so much that eventually we could no longer resolve a single interference fringe in the field of view during the experiment. For these fractures we have time-dependent closure data taken in situ for only part of the closure process. We had to determine the final aperture from the recovered samples. If, in a subsequent study, a standard temperature and pressure path were used with fractures of standard length, more quantitative closure rate data could be obtained, possibly extending observations to temperatures of $200^{\circ} \mathrm{C}$ and below.

\section{Conclusions}

[28] Rapid fracture closure occurs in quartz single crystals at hydrothermal conditions, providing up to $80 \%$ loss of fracture volume. Closure is inferred to result from the dissolution of debris that props the fracture open. The experimental results are consistent with pressure solution dissolution of the prop driven by high stress at the contact between the prop and the fracture face. The driving force for closure in experiments is stored elastic energy in the sample. Fracture closure through solution mass transfer may be an important mechanism for short-term porosity reduction and mechanical strengthening for materials containing fractures where normal stress exceeds pore fluid pressure, such as might be generated during earthquake rupture. The ratecontrolling mechanism of closure is not constrained by the experiments; however, models of reaction and diffusion rate limited closure are consistent with the observations. Rates of fracture closure have not been extrapolated to pressures and temperatures corresponding to earthquake nucleation depths, primarily because of the uncertainties associated with natural fracture volume geometry and stress state. An important consideration in extrapolating the data is that the macroscopic differential stress is expected to be much greater in the Earth, thus increasing the closure rate. Furthermore, unlike the fractures in the current study, the driving stress for fracture closure in natural fault zones will not be significantly reduced during the early stages of closure, allowing this process to proceed toward completion at a greater rate. On the other hand, temperatures may be $200-300^{\circ} \mathrm{C}$ cooler at earthquake nucleation depths than the maximum temperature in our experiments, reducing the naturally observed closure rate.

\section{Appendix A: Rate Equations for Fracture Closure}

\section{A1. Interface Rate Limited Case}

[29] If the removal of material at the prop is governed by the rate of dissolution, then

$$
\frac{d m}{d t}=k_{+}\left(1-\frac{C_{0}}{C}\right),
$$

where material $m$ added to the solution from the prop is taken as positive $\left(\mathrm{mol} / \mathrm{m}^{2}\right), k_{+}$is the dissolution rate constant $\left(\mathrm{mol} / \mathrm{m}^{2} \mathrm{~s}\right), C$ is the concentration of silica (activity or mole fraction, dimensionless) at the contact, and $C_{0}$ is the concentration of silica in the bulk solution adjacent to the contact [Dove and Crerar, 1990]. From equation (4), assuming that only the third term is significant and $C_{0}$ is a constant and applying the standard definition of activity, we find that

$$
\frac{C}{C_{0}}=\exp \left(\frac{-\sigma_{n}^{c} V_{m}}{R T}\right),
$$

where $\sigma_{n}^{c}$ is the normal stress at the contact in excess of fluid pressure. If the argument of the exponential in equation (A2) is much less than 1 , then $e^{-x} \approx 1-x$, and combining equations (A1) and (A2) yields

$$
\frac{d m}{d t} \approx \frac{k_{+} \sigma_{n}^{c} V_{m}}{R T} .
$$




\section{Fracture closure model geometry}

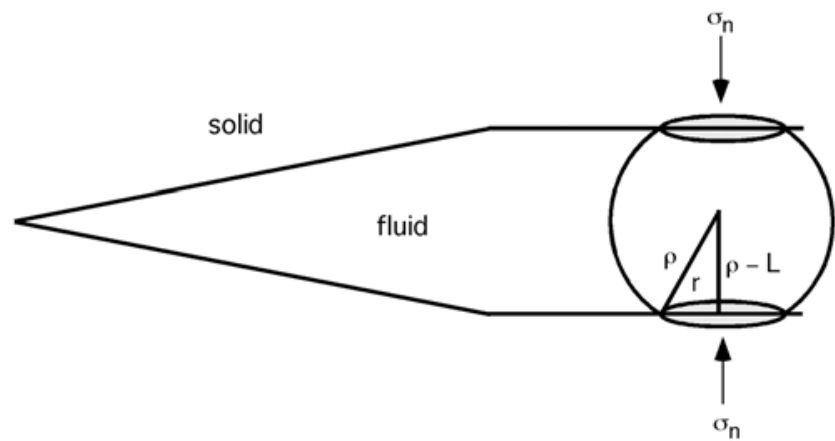

Figure A1. Spherical prop geometry used in the model of fracture closure. Aperture and propping particle size are exaggerated for illustrative purposes.

If the dissolution rate is considered uniform over the entire contact, then the closure rate is

$$
\frac{d L}{d t}=\frac{d m}{d t} V_{m} \approx \frac{k_{+} \sigma_{n}^{c} V_{m}^{2}}{R T}
$$

where $L$ is closure (m). Equation (A4) is the standard form for interface rate limited pressure solution [e.g., Raj, 1982; Raj and Chung, 1981]. The stress at a contact between a propping particle and the fracture wall will decrease with closure as the contact area increases with $L$ (if the prop is not rectangular) and as the stored elastic energy is relaxed.
Ignoring elastic shape change of the particle, for a spherical particle (Figure A1), the average contact normal stress is

$$
\sigma_{n}^{c}=\frac{f+s(\rho-L)}{\pi\left(\rho^{2}-(\rho-L)^{2}\right)},
$$

where $f$ is the applied normal force $(\mathrm{N}), s$ is the crack stiffness $(\mathrm{N} / \mathrm{m})$, and $\rho$ is the radius of the propping particle (m).

[30] In our experiments the pore fluid and the fracture are subject to macroscopic hydrostatic conditions, which means that $f=0$ in equation (A5). Using these substitutions and the condition that $T$ is constant with time requires $k_{+}$and $C_{0}$ to be constant. Combining equations (A4) and (A5) yields

$$
\frac{d L}{d t} \approx \frac{k_{+} V_{m}^{2} s(\rho-L)}{R T \pi\left(\rho^{2}-(\rho-L)^{2}\right)},
$$

whose solution, if the starting value of $L=0$, is

$$
L^{2}-\rho L-\rho^{2} \ln (\rho-L)+\rho^{2} \ln (\rho)=\frac{s k_{+} V_{m}^{2} t}{\pi R T} .
$$

The form of equation (A7) is shown in Figure A2. It is exponential-like but predicts a more rapid closure at small ellapsed times than actually observed (Figure A2). Closure equations (A7) and (A12) close completely at long time, whereas the actual observation is that there is residual crack aperture due to inelastic processes. To

\section{Equilibrium fracture closure}

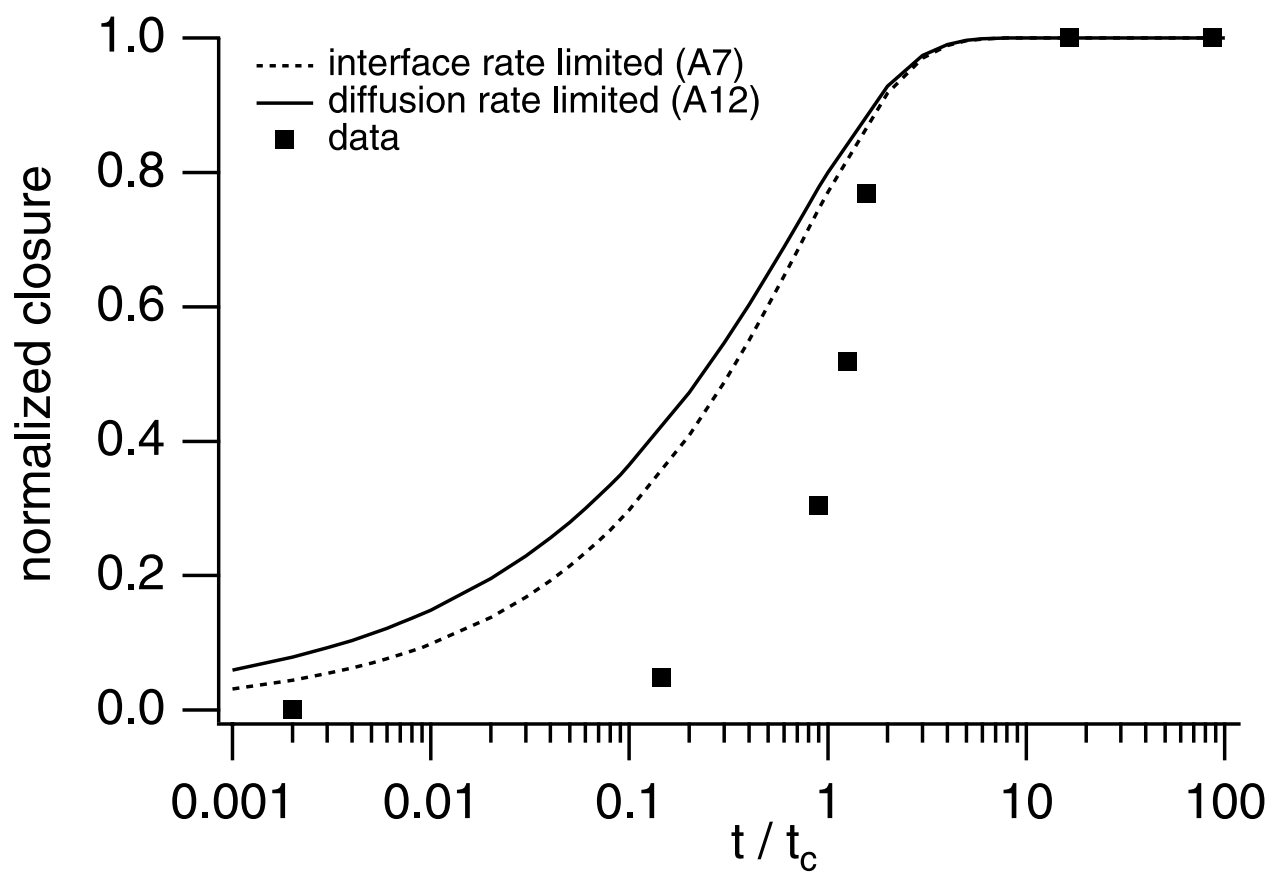

Figure A2. Nonequilibrium data (qch 12), contrasted with the functional form of fracture closure relationships, equations (A7) and (A12) calculated at equilibrium conditions (constant temperature, pressure, and concentration) using the spherical prop model (Figure A1) and kinetic considerations. 
reconcile model equations with the observations, $\rho$ can be considered to be an effective starting half aperture, different from the actual opening by a constant equal to the residual aperture at very long times.

\section{A2. Diffusion Rate Limited Case}

[31] If the removal of material at the prop is rate limited by the rate of diffusion, then from Fick's first law

$$
\frac{d m}{d t}=-\frac{D C_{0} \nabla \mu}{V_{m} R T},
$$

where $m$ has the same dimensions as in equation (A1), $D$ is the diffusion coefficient $\left(\mathrm{mol} / \mathrm{m}^{2} \mathrm{~s}\right)$, and $\nabla \mu$ is the chemical potential gradient [e.g., Hickman and Evans, 1992]. Assuming, as was done for the interface limited case, that the chemical potential is given by the last term in equation (4), then an approximate expression for this gradient is given by dividing this term by a characteristic diffusion distance $\Lambda$,

$$
\nabla \mu=\frac{\sigma_{n}^{c} V_{m}}{\Lambda} .
$$

If the rate of removal is uniform over the entire contact, then the fracture closure rate is

$$
\frac{d L}{d t}=\frac{d m}{d t} V_{m}=\frac{D C_{0} V_{m} \sigma_{n}^{c}}{\Lambda R T}
$$

which is the standard form for the diffusion rate limited pressure solution [Rutter, 1976]. For the geometry of Figure A1 the average diffusion distance $\Lambda=r / 2=\left[\rho^{2}-\right.$ $\left.(\rho-L)^{2}\right]^{1 / 2} / 2$, where $r$ is the contact radius. Making this substitution in equation (A10) and combining with equation (A5), under the restriction $f=0$ appropriate for the experiments, yields

$$
\frac{d L}{d t}=\frac{d m}{d t} V_{m}=\frac{2 s D C_{0} V_{m}(\rho-L)}{\pi R T\left[\rho^{2}-(\rho-L)^{2}\right]^{3 / 2}} .
$$

The solution of equation (A11) if the starting value of $L=0$ at constant $T, D$, and $C_{0}$ is

$$
\begin{gathered}
-\frac{1}{3} \cos ^{3}\left(\sin ^{-1} \frac{\rho-L}{\rho}\right)-\cos \left(\sin ^{-1} \frac{\rho-L}{\rho}\right)-\ln \mid \csc \left(\sin ^{-1} \frac{\rho-L}{\rho}\right) \\
+\cot \left(\sin ^{-1} \frac{\rho-L}{\rho}\right) \mid=\frac{2 s D C_{0} V_{m} t}{\pi R T}, \quad \text { (A12) }
\end{gathered}
$$

which is shown in Figure A2. The form is nearly exponential in time but more rapid than actually observed. The form is quite similar to that of the interface rate limited case in equation (A7).

[32] Acknowledgments. Discussion, suggestions, tools, and equipment contributed by Brian Kilgore and John Pinkston are gratefully acknowledged. Particle size analysis was done by David Bach of the U.S. Silica Company. Michele Cooke provided guidance and instruction in the boundary element method. John Farver suggested references on silica diffusion in water. This paper was significantly improved in response to comments by C. Morrow, F. Renard, Y. Kharaka, and B. Ngwenya; many thanks to them. We are especially grateful to Sue Brantley and Kevin Shelton for providing unpublished details and observations from their previous studies of crack healing and fluid inclusion formation in quartz.
This study was supported by the USGS Earthquake Hazards and Deep Continental Studies Programs.

\section{References}

Atkins, P. W. (1982), Physical Chemistry, 1095 pp., W. H. Freeman, New York.

Beeler, N. M., and S. H. Hickman (1996), Crack healing in quartz: Experiments and theoretical considerations, Eos Trans. $A G U, 77(46)$, Fall Meet. Suppl., F696.

Blakely, J. M. (1973), Introduction to the Properties of Crystal Surfaces, 261 pp., Pergamon, New York.

Brace, W. F., and J. B. Walsh (1962), Some direct measurements of the surface energy of quartz and orthoclase, Am. Mineral., 47, 1111-1122.

Brantley, S. L. (1992), The effect of fluid chemistry on quartz microcrack lifetimes, Earth Planet. Sci. Lett., 113, 145-156.

Brantley, S. L., B. Evans, S. H. Hickman, and D. A. Crerar (1990), Healing of microcracks in quartz: Implications for fluid flow, Geology, 18, 136-139.

Bruhn, R. L., W. T. Parry, W. A. Yonkee, and T. Thompson (1994), Fracturing and hydrothermal alteration in normal fault zones, Pure Appl. Geophys., 142, 609-645.

Burnham, C. W., J. R. Holloway, and N. F. Davis (1969), Thermodynamic properties of water at $1000^{\circ} \mathrm{C}$ and $10 \mathrm{~kb}$, Spec. Pap.Geol. Soc. Am., 132, $96 \mathrm{pp}$.

Chester, F. M., and J. S. Chester (2000), Stress and deformation along wavy frictional faults, J. Geophys. Res., 105, 23,421-23,430.

Chester, F. M., J. P. Evans, and R. L. Biegel (1993), Internal structure and weakening mechanisms of the San Andreas fault, J. Geophys. Res., 98, $771-786$.

Crouch, S. L., and A. M. Starfield (1990), Boundary Element Methods in Solid Mechanics, 322 pp., Chapman and Hall, New York.

Dieterich, J. H., and B. D. Kilgore (1996), Imaging surface contacts: Power law contact distributions and contact stresses in quartz, calcite, glass and acrylic plastic, Tectonophysics, 256, 219-239.

Dove, P. M., and D. A. Crerar (1990), Kinetics of quartz dissolution in electrolyte solutions using a hydrothermal mixed flow reactor, Geochim. Cosmochim. Acta, 54, 955-969.

Fournier, R. O., and R. W. Potter (1982), An equation correlating the solubility of quartz in water from $25^{\circ}$ to $900^{\circ} \mathrm{C}$ at pressures up to $10 \mathrm{~kb}$, Geochim. Cosmochim. Acta, 46, 1969-1973.

Hay, R. S., and B. Evans (1988), Intergranular distribution of pore fluid and the nature of high-angle grain boundaries in limestone and marble, J. Geophys. Res., 93, 8959-8974.

Hickman, S. H., and B. Evans (1986), Diffusional crack healing in $\mathrm{NaCl}$ in the presence of a saturated brine solution (abstract), Eos Trans. AGU, 67, 1202.

Hickman, S. H., and B. Evans (1987), Influence of geometry upon crack healing rate in calcite, Phys. Chem. Miner., 15, 91-102.

Hickman, S. H., and B. Evans (1992), Growth of grain contacts in halite by solution transfer; Implications for diagenesis, lithification, and strength recovery, in Fault Mechanics and Transport Properties of Rocks, edited by B. Evans and T.-f. Wong, pp. 253-280, Academic, San Diego, Calif.

Ildefonse, J.-P., and V. Gabis (1976), Experimental study of silica diffusion during metasomatic reactions in the presence of water at $550^{\circ} \mathrm{C}$ and 1000 bars, Geochim. Cosmochim. Acta, 40, 297-303.

Leamnson, R. N., J. Thomas Jr., and H. P. Ehrlinger III (1969), A study of the surface areas of particulate microcrystalline silica and silica sand, Ill. State Geol. Surv. Circ., 444, $11 \mathrm{pp}$

Li, Y.-G., J. E. Vidale, K. Aki, F. Xu, and T. Burdette (1998a), Evidence of shallow fault zone strengthening after the 1992 M7.5 Landers, California, earthquake, Science, 279, 217-219.

Li, Y.-G., K. Aki, and J. E. Vidale (1998b), Observations of fault-zone trapped waves at active faults support broken-then-healing cycle on earthquake faults, Eos Trans. AGU, 79(17), Spring Meet. Suppl., S220.

Lockner, D. A., and J. D. Byerlee (1995), An earthquake instability model based on faults containing high fluid-pressure compartments, Pure Appl. Geophys., 145, 717-745.

Martin, R. J. (1972), Time-dependent crack growth in quartz and its application to creep of rocks, J. Geophys. Res., 77, 1406-1419.

Massonnet, D., W. Thatcher, and H. Vadon (1996), Detection of postseismic fault-zone collapse following the Landers earthquake, Nature, 382, $612-$ 616.

Moore, D. E., D. A. Lockner, and J. D. Byerlee (1994), Reduction of permeability in granite at elevated temperatures, Science, 265, 15581561.

Morrow, C. A., and D. A. Lockner (1994), Permeability differences between surface-derived and deep drillhole core samples, Geophys. Res. Lett., 21, 2151-2154.

Nadeau, R. M., and L. R. Johnson (1998), Seismological studies at Parkfield VI: Moment release rates and estimates of source parameters for small repeating earthquakes, Bull. Seismol. Soc. Am., 88, 790-814. 
Ostwald, W. (1895), The Scientific Foundations of Analytical Chemistry Treated in an Elementary Manner, MacMillan, Old Tappan, N. J.

Parry, W. T., and R. L. Bruhn (1990), Fluid pressure transients on seismogenic normal faults, Tectonophysics, 179, 335-344.

Raj, R. (1982), Creep in polycrystalline aggregates by matter transport through a liquid phase, J. Geophys. Res., 87, 4731-4739.

Raj, R., and C. K. Chung (1981), Solution-precipitation creep in glass ceramics, Acta Metall., 29, 159-166.

Rice, J. R. (1992), Fault stress states, pore pressure distributions, and the weakness of the San Andreas Fault, in Fault Mechanics and Transport Properties of Rocks, edited by B. Evans and T.-f. Wong, pp. 475-503, Academic, San Diego, Calif.

Rimstidt, J. D., and H. L. Barnes (1980), The kinetics of silica-water reactions, Geochim. Cosmochim. Acta, 44, 1683-1699.

Robin, P.-Y. (1978), Pressure solution at grain-to-grain contacts, Geochim. Cosmochim. Acta, 42, 1383-1389.

Rossi, B. (1965), Optics, 510 pp., Addison-Wesley-Longman, Reading, Mass.

Rutter, E. H. (1976), The kinetics of rock deformation by pressure solution, Philos. Trans. R. Soc. London, Ser. A, 283, 203-219.
Sammis, C. G., R. M. Nadeau, and L. R. Johnson (1999), How strong is an asperity?, J. Geophys. Res., 104, 10,609-10,619.

Shelton, K. L., and P. M. Orville (1980), Formation of synthetic fluid inclusions in natural quartz, Am. Mineral., 65, 1233-1236.

Sleep, N. H., and M. L. Blanpied (1992), Creep, compaction and the weak rheology of major faults, Nature, 359, 687-692.

Sleep, N. H., and M. L. Blanpied (1994), Ductile creep and compaction: A mechanism for transiently increasing fluid pressure in mostly sealed faults, Pure Appl. Geophys., 143, 9-40.

Smith, D. L., and B. Evans (1984), Diffusional crack healing in quartz J. Geophys. Res., 89, 4125-4136.

Stumm, W., and J. J. Morgan (1981), Aquatic Chemistry, 780 pp., John Wiley, Hoboken, N. J.

Walsh, J. B., and W. F. Brace (1984), The effect of pressure on porosity and the transport properties of rock, J. Geophys. Res., 89, 9425-9431.

N. M. Beeler and S. H. Hickman, U.S. Geological Survey, Earthquake Hazards Team, MS 977, 345 Middlefield Road, Menlo Park, CA 94025, USA. (nbeeler@usgs.gov; hickman@usgs.gov) 